\title{
Mechanical, Morphological and Thermal Characterization of Compatibilized Poly(lactic acid)/Thermoplastic Starch Blends
}

\author{
L. Lendvai ${ }^{1,2, *}$, D. Brenn ${ }^{2}$ \\ ${ }^{1}$ Széchenyi István University, Department of Materials Science and \\ Engineering \\ Egyetem tér 1, H-9026 Győr, Hungary \\ *e-mail: lendvai.laszlo@sze.hu
}

${ }^{2}$ Budapest University of Technology and Economics, Department of Polymer Engineering Múegyetem rkp. 3, H-1111 Budapest, Hungary

Abstract: A two-step compounding procedure was used to produce binary blends composed of poly(lactic acid) (PLA) and thermoplastic starch (TPS) with varying component ratios. Subsequently, three different chemical connectors were introduced in order to enhance the interfacial adhesion between the PLA and the TPS. Maleic anhydride, blocked isocyanate, and chain extender were used as coupling agents. Mechanical, morphological and thermal properties of PLA/TPS blends were determined. It was revealed that the initial interfacial adhesion between the components is weak. Out of the three coupling agents introduced, the chain extender proved to be the most effective, however, the improvement achieved in the mechanical properties was still marginal. According to the thermogravimetric analysis thermal stability was not significantly affected by any of the coupling agents.

Keywords: thermoplastic starch; poly(lactic acid); compatibilization; polymer blend

\section{Introduction}

In the recent decades, there has been an increasing interest in reducing the amount of the waste caused by the disposable plastic products. In order to achieve this, 
considerable efforts have been devoted to replace oil-based, non-degradable plastics with natural and biodegradable polymeric materials.

Starch is considered as one of the most promising candidate due to its high availability and low price. Native starch is a semi-crystalline polymer, a polysaccharide composed of amylose and amylopectin. Starch itself does not have any thermoplastic properties [1]. However, with suitable plasticizers (water, glycerol, sorbitol, etc.) it can be brought into a gelatinized form, which is called thermoplastic starch (TPS). TPS can already be processed with common thermoplastic technologies like extrusion, injection molding [2] or solution casting [3]. Despite the lots of benefits, TPS also has its drawbacks: moisture sensitivity poor mechanical properties and significant property change with elapsed time. Also a high amount of studies dealt with the topic of compounding starch with ecofriendly polyesters, such as poly(lactic acid) (PLA) [4], polycaprolactone (PCL) [5] or poly(butylene adipate-co-terephthalate) [6] in order to reduce their production costs and to preserve their biodegradable characteristics.

PLA is a semi-crystalline biodegradable polyester that can be made from renewable resources [7]. Due to its outstanding strength, stiffness, biocompatibility and transparency it is widely used for medical, agricultural and packaging applications [8]. In the meanwhile, PLA has relatively high production costs, it is brittle and presents limited gas barrier properties. Blending PLA with TPS could be a good strategy to obtain a more cost-efficient biodegradable material. Some works have been devoted in the recent years to the development of PLA/TPS blends [9]. Nevertheless, PLA and TPS are thermodynamically incompatible, since the interfacial adhesion between the hydrophobic PLA and the hydrophilic TPS is rather poor.

In the recent years numerous studies investigated the possibilities of introducing different reactive coupling agents in order to enhance the interfacial adhesion between TPS and PLA. When attempting to improve the mechanical properties of PLA/TPS blends, the most common way is the use of reactive compatibilizers [4].

Several researchers added difunctional molecules with high reactivity, such as methylenediphenyl diisocyanate (MDI) [10] or hexamethylene diisocyanate (HDI) [11] in order to achieve a better adhesion between the components. Hydroxyl and carboxyl groups both in TPS and PLA molecules are expected to interact with the isocyanate groups, therefore enhancing the bond between the two polymers. Note, that both MDI and HDI are recorded as harmful substances by the EU Commission Communication 2008/C 34/01 [4]. There is also an issue related to the high reactivity of commercially available chemicals: the isocyanate groups associated with urethane crosslinkers are reactive towards many other compounds. This reactivity can lead to stability problems due to the ability of NCO groups to react with atmospheric 
moisture. The recently introduced blocking technology of Lanxess enables the isocyanates to remain stable on room temperature and to be thermally re-activated. By choosing a suitable blocked isocyanate grade (with a reactivation temperature just below processing temperature) it is possible to graft it on the TPS or PLA in situ during a reactive melt blending, thereby making the preliminary grafting procedure unnecessary.

Anhydrides with unsaturated bonds have also been used in polymer compatibilization. For the grafting procedure one requires an organic peroxide as free-radical initiator [12]. Orozco [13] and his group functionalized PLA with maleic anhydride (MA) through reactive melt blending. They used dicumyl peroxide (DCP) as an initiator of the grafting process. According to the SEM analysis the MA enhanced the compatibility between the PLA and TPS showing a stable, homogenous interface.

Attempts have been made to improve the adhesion between the components using commercial chain extenders (CE) as well. Chain extenders are molecules with functional properties that reconnect polymer chains that have broken due to degradation. The functional groups of these extender molecules are reactive with hydroxyl, carboxyl and isocyanate groups making it a promising connector between TPS and PLA. Zhang et al. [14] observed that the presence of CE facilitates a better dispersion of components and enhances the compatibility between the PLA and TPS. It was also pointed out [15] that CE only causes a marginal improvement when used together with MA-based compatibilization.

Unfortunately, the mechanical properties of the TPS component drastically depend on the humidity, plasticizer type/content and the processing parameters. Therefore, a wide range of tensile strength (0.4-38 MPa) and elongation at break (1-129\%) values can be found in the literature [4]. Accordingly, the results obtained by the different studies regarding the effects of various coupling agents are difficult to compare.

Here, PLA/TPS blends were prepared via batchwise melt mixing with and without reactive compatibilization. Firstly, blends with different PLA/TPS ratios were prepared and characterized. Subsequently the sample containing $75 \mathrm{wt} \%$ PLA and $25 \mathrm{wt} \%$ TPS was prepared with different chemical connectors: (i) maleic anhydride with dicumyl peroxide as grafting initiator, (ii) blocked isocyanate and (iii) chain extender (multifunctional oligomer). The paper focuses on the assessment of mechanical, morphological and thermal properties of the prepared blends. 


\section{Experimental}

\subsection{Materials}

The TPS was produced with native maize starch (Hungramid F Meritena 100) supplied by Brenntag Ltd (Budapest, Hungary). As plasticizers of starch glycerol and distillated water was used. The glycerol (purity of 99.5\%) was obtained from a local supplier (Csepp Bt.; Budapest, Hungary). Stearic acid obtained from ICC Chemol Ltd. (Budapest, Hungary) was used as lubricant when processing TPS. The PLA (Ingeo 3052D) was obtained from NatureWorks LLC (Minnetonka, USA).

The MA was purchased from Sigma-Aldrich Chemie GmbH (Munich, Germany). The DCP (Retic DCP 40 MG) was obtained from Oxido s.r.l. (Anagni, Italy). Commercially available CE (Joncryl ADR®-4368C) was supplied by BASF SE (Ludwigshafen, Germany). The blocked isocyanate (Trixene BI 7963) hexamethylene diisocyanate blocked with diethyl malonate (bHDI) - was purchased from Lanxess Urethanes UK Ltd. (Accrington, UK).

\subsection{Processing of the materials}

Prior to processing the maize starch was conditioned in a Memmert HCP153 humidification chamber (Frankfurt, Germany) at $30^{\circ} \mathrm{C}$ and a relative humidity (RH) of $50 \%$ for $24 \mathrm{~h}$. Subsequently, the starch, the plasticizers and the lubricant were weighed according to Table 1 and premixed manually to obtain a "dry mixture".

Table 1. The recipe of the TPS

\begin{tabular}{cccc}
\hline $\begin{array}{c}\text { Starch } \\
\text { [wt\%] }\end{array}$ & $\begin{array}{c}\text { Glycerol } \\
\text { [wt\%] }\end{array}$ & $\begin{array}{c}\text { Distilled water } \\
\text { [wt\%] }\end{array}$ & $\begin{array}{c}\text { Stearic acid } \\
\text { [wt\%] }\end{array}$ \\
\hline 66 & 16.5 & 16.5 & 1 \\
\hline
\end{tabular}

The prepared "dry mixture" was melt-compounded in a Labtech LTE 26-44 type twin-screw extruder (Samutprakan, Thailand) with a screw diameter of $26 \mathrm{~mm}$ and $\mathrm{L} / \mathrm{D}$ ratio of 44 . The heating zones of the extruder barrel were maintained at a temperature of $85,90,95,100,100,100,110,110,120,120^{\circ} \mathrm{C}$ from feed zone to die end, respectively. The screw speed was set to $75 \mathrm{rpm}$. Starve feeding of the extruder was done manually. The extruder barrel was equipped with an atmospheric vent to remove the vaporized water. After the melt compounding, the obtained TPS was pelletized.

Prior to the blending of the components the TPS granules were conditioned at $30{ }^{\circ} \mathrm{C}$ and $50 \% \mathrm{RH}$ for $24 \mathrm{~h}$, while the PLA pellets were dried in a drying chamber at $80{ }^{\circ} \mathrm{C}$ for $4 \mathrm{~h}$. The PLA/TPS blends were produced in a Brabender Plasti-Corder 
PL2000 type kneading chamber (Duisburg, Germany). The screw speed was set to $50 \mathrm{rpm}$, the temperature of the mixing chamber was $170{ }^{\circ} \mathrm{C}$. Table 2 shows the composition of the prepared mixtures. The amount of coupling agents introduced was an average value determined based on the literature [4].

Table 2. The recipe of the PLA/TPS blends

\begin{tabular}{c|cccccc}
\hline Sample & $\begin{array}{c}\text { PLA } \\
\text { [wt \%] }\end{array}$ & $\begin{array}{c}\text { TPS } \\
\text { [wt\%] }\end{array}$ & $\begin{array}{c}\text { DCP } \\
\text { [phr] }\end{array}$ & $\begin{array}{c}\text { MA } \\
\text { [phr] }\end{array}$ & $\begin{array}{c}\text { bHDI } \\
\text { [phr] }\end{array}$ & $\begin{array}{c}\text { CE } \\
\text { [phr] }\end{array}$ \\
\hline PLA & 100 & - & - & - & - & - \\
PLA/TPS25 & 75 & 25 & - & - & - & - \\
PLA/TPS50 & 50 & 50 & - & - & - & - \\
PLA/TPS75 & 25 & 75 & - & - & - & - \\
TPS & - & 100 & - & - & - & - \\
PLA/TPS_MA & 75 & 25 & 0.25 & 2.5 & - & - \\
PLA/TPS_bHDI & 75 & 25 & - & - & 2.5 & - \\
PLA/TPS_CE & 75 & 25 & - & - & - & 0.5 \\
\hline
\end{tabular}

In the next step, all the prepared blends were compression molded into sheets of $1.25 \mathrm{~mm}$ thickness in a Collin Teach-Line Platen Press 200E hot press machine (Munich, Germany) at the temperature of $170{ }^{\circ} \mathrm{C}$ and a pressure of 25 bar for 5 mins. Specimens for testing were cut out of the compression molded sheets with a Mutronic Diadisk cutter (Rieden, Germany).

\subsection{Characterization}

Samples were conditioned under the same circumstances $\left(30^{\circ} \mathrm{C}, 50 \% \mathrm{RH}\right)$ for at least $48 \mathrm{~h}$ prior to the tests in order to obtain reproducible results.

The mechanical properties were determined by tensile tests performed on a universal testing machine (Zwick Z020, Ulm, Germany) equipped with a $20 \mathrm{kN}$ sensor at a tensile speed of $5 \mathrm{~mm} / \mathrm{min}$. Specimen type: 3 according to EN ISO 8256 were used for tensile tests. The tests were performed at room temperature. The average values were derived from five parallel measurements.

A scanning electron microscope (SEM) JEOL JSM 6380LA (Tokyo, Japan) was used to observe the fracture surfaces of the PLA/TPS blends. Prior to their inspection, the samples were sputter-coated with gold/palladium alloy.

Thermogravimetric analysis (TGA) was performed with a TGA Q500 analyzer (TA Instruments, New Castle, New Jersey, USA) to examine the thermal stability of the samples. Tests were carried out by heating up samples of $4 \pm 1 \mathrm{mg}$ from room temperature to $500{ }^{\circ} \mathrm{C}$ at a heating rate of $10^{\circ} \mathrm{C} \mathrm{min}^{-1}$ under nitrogen purge with a flow rate of $60 \mathrm{ml} / \mathrm{min}$. 


\section{Results and discussion}

\subsection{Tensile mechanical properties}

The tensile mechanical properties of non-compatibilized PLA/TPS blends are summarized in Fig. 1. It can be observed that PLA has a significantly higher yield strength (50 MPa > $10 \mathrm{MPa}$ ) and Young's modulus (1.9 GPa > 1.3 GPa) than TPS. Interestingly, with respect to elongation at yield point PLA also outperforms TPS $(4.0 \%>0.9 \%)$. This indicates that TPS has a rigid behavior, which can be attributed to the relatively high processing temperature. The mechanical properties of the PLA/TPS blends show a minimum at $75 \mathrm{wt} \%$ TPS content. Presumably at this point TPS can be considered as the continuous phase, which contains PLA segments acting as failure sites. These results also refer to a poor adhesion between the components and are in good agreement with the corresponding literature [16].
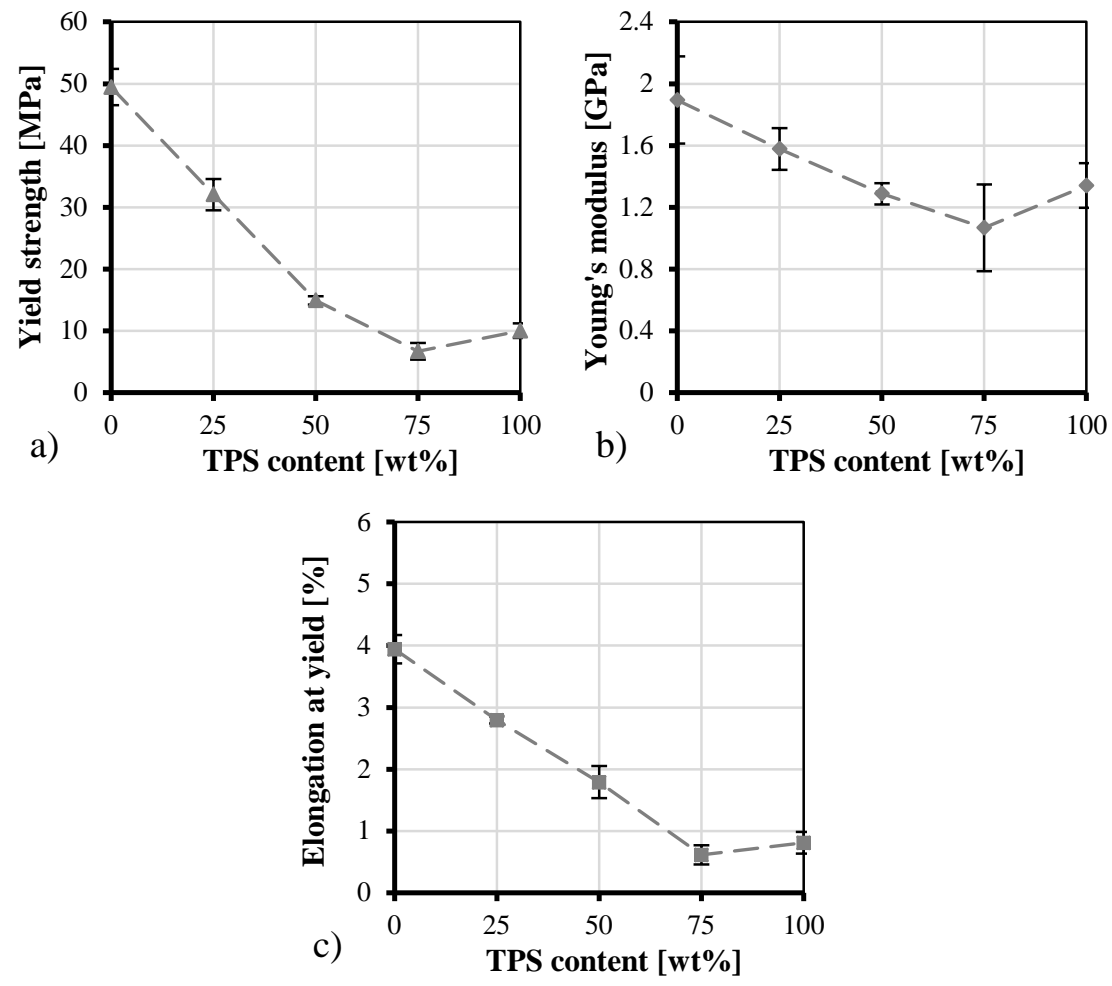

Figure 1. Yield strength (a), Young's modulus (b) and elongation at yield (c) of PLA/TPS blends as a function of TPS content 
The tensile mechanical properties of the compatibilized blends containing $75 \mathrm{wt} \%$ PLA and 25 wt\% TPS compared to the non-compatibilized PLA/TPS25 sample are shown in Fig. 2. It can be observed, that all type of coupling agents increased the elongation of the PLA/TPS blend relatively by 20\% (from $27 \%$ to $32 \%$ ). In the meanwhile, the changes in tensile strength differ depending on the type of the coupling agent introduced. The strength of the MA-compatibilized blend was similar to that of neat PLA/TPS25, however, using bHDI as additive decreased it slightly. After CE was added the strength increased from $32 \mathrm{MPa}$ to $38 \mathrm{MPa}$, which could be attributed to the improved adhesion between the components. The changes in Young's modulus were within the deviation range in each case.

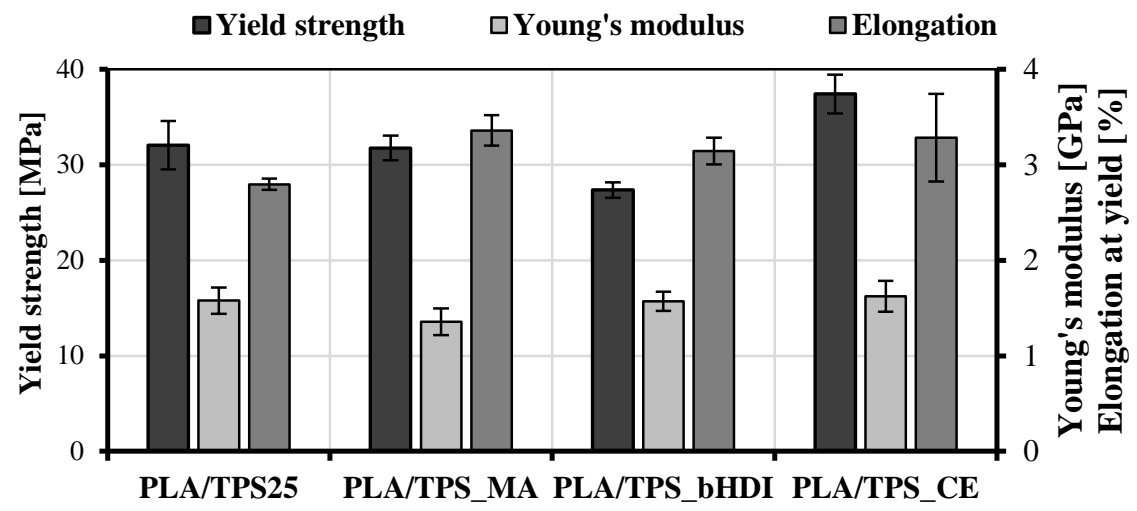

Figure 2. Yield strength, Young's modulus and elongation at yield of the samples PLA/TPS25, PLA/TPS_MA, PLA/TPS_bHDI and PLA/TPS_CE

\subsection{Morphological properties}

Fig. 3 reveals the SEM images of the samples PLA, TPS and PLA/TPS50. Fig. 3a and $3 \mathrm{~b}$ show that both TPS and PLA have a homogenous, rigid fracture surface. Conversely, the blend in between reveals an inhomogeneous surface with cracks and cavities. Fig. 3c substantiates the assumption made based on the mechanical results, namely, that the adhesion between the two components is rather poor. 


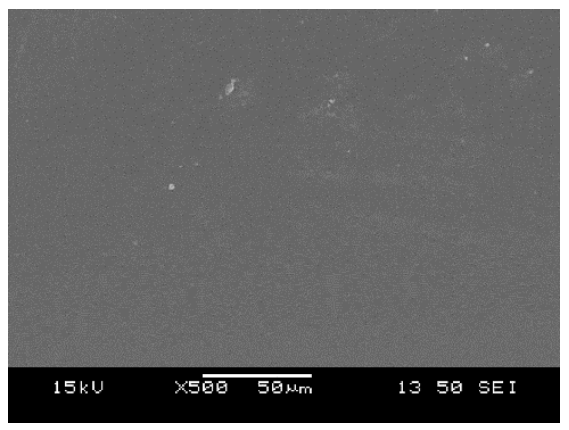

a)

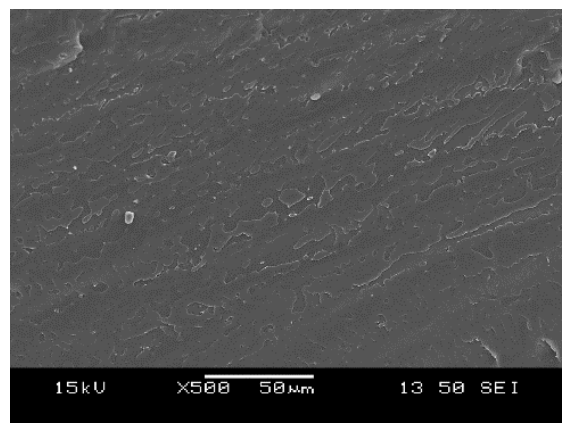

b)

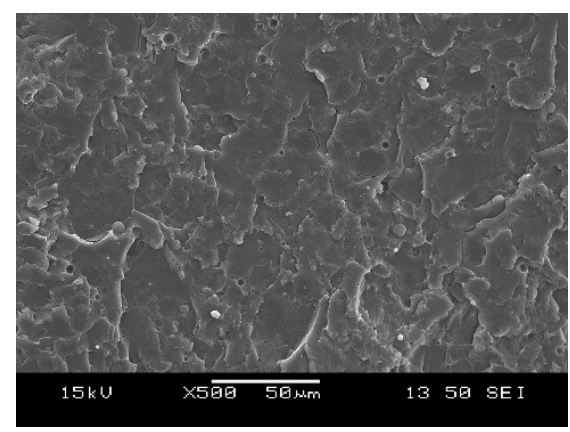

c)

Figure 3. SEM images of the samples TPS (a), PLA (b) and PLA/TPS50 (c)

Fig. 4 shows the SEM images taken of the fracture surface of the PLA/TPS25 sample and its compatibilized variants. The PLA/TPS25 sample shows an inhomogenous characteristics, similar to PLA/TPS50. The fracture surfaces of compatibilized blends are also inhomogeneous, however in these cases little to no stress fractures, cavities or cracks can be observed. Also, the interface between the components seems much more stable and homogenous. These conclusions are in good accordance with the increased elongation values that were measured during the tensile tests. 


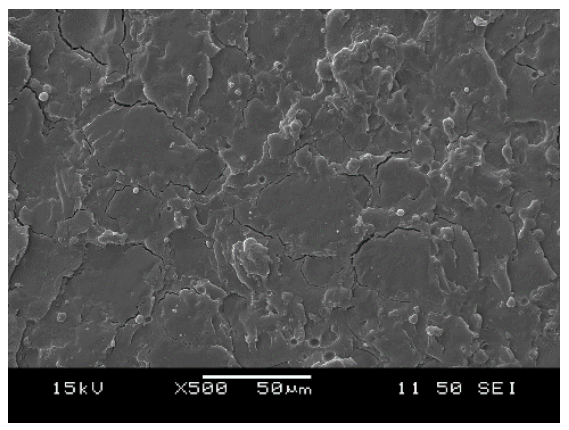

a)

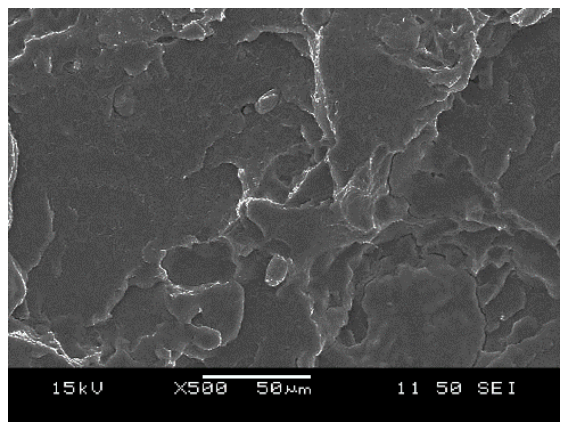

C)

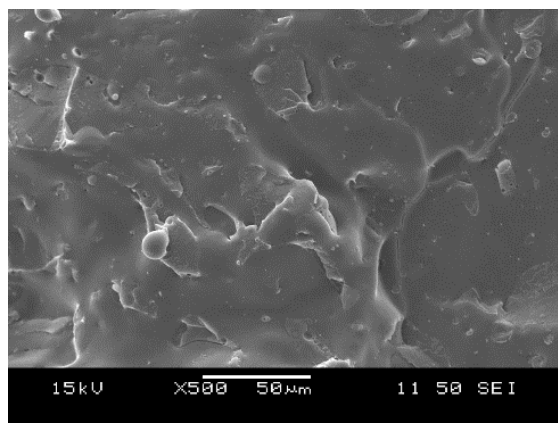

b)

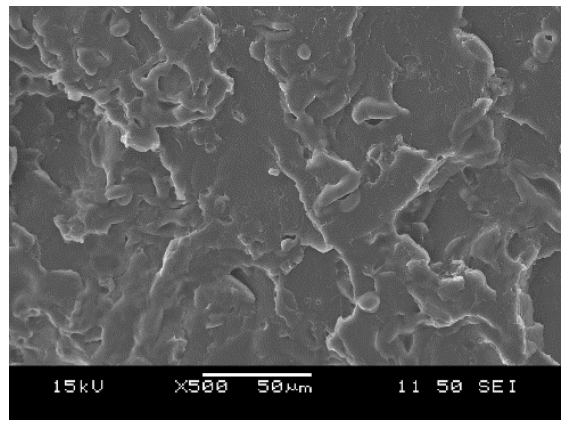

d)

Figure 4. SEM images of the samples PLA/TPS25 (a) PLA/TPS_MA (b), PLA/TPS_bHDI (c) and PLA/TPS_CE (d).

\subsection{TGA behavior}

Fig. 5a shows the TGA traces, whereas Fig. 5b shows its derivatives (DTG) for PLA, TPS and the neat PLA/TPS blends. According to the literature, the thermal decomposition of TPS components takes place below $350{ }^{\circ} \mathrm{C}$, while the thermal degradation processes observed above $350^{\circ} \mathrm{C}$ are related to the PLA [9]. The TPS containing samples underwent a two-step degradation. The first transition that can be observed between $50-250{ }^{\circ} \mathrm{C}$ is related to the elimination of water, glycerol and other low molecular weight compounds [17]. The second - and more significant transition is related to the thermal decomposition of TPS. The neat PLA decomposed in one step at $\sim 360{ }^{\circ} \mathrm{C}$. 

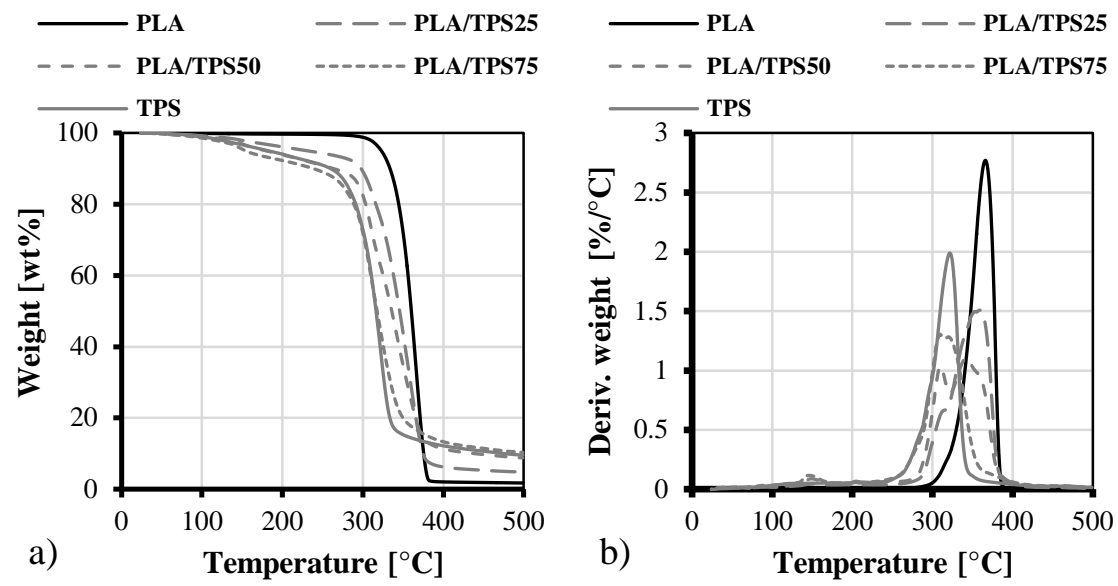

Figure 5. TGA (a) and DTG (b) curves of PLA, TPS and the non-compatibilized PLA/TPS blends

Table 3 lists the temperature values derived from the TGA curves corresponding to $10,25,50,75 \%$ mass losses. Besides, the maximum values of peaks appearing in DTG curves corresponding to the degradation of TPS ( $\left.\mathrm{T}_{\mathrm{pTPS}}\right)$ and PLA ( $\left.\mathrm{T}_{\mathrm{pPLA}}\right)$, and the residual mass (char) is also listed. Based on the data it can be assumed that blending PLA with TPS decreases the thermal stability of both components. The char formation (residual mass) at higher temperature was mostly due to the TPS phase.

Table 3. TGA data determined for PLA, TPS and the non-compatibilized PLA/TPS blends

\begin{tabular}{c|ccccccc}
\hline Sample & $\begin{array}{c}\mathbf{T}_{\mathbf{1 0}} \\
{\left[{ }^{\circ} \mathbf{C}\right]}\end{array}$ & $\begin{array}{c}\mathbf{T}_{\mathbf{2 5}} \\
{\left[{ }^{\circ} \mathbf{C}\right]}\end{array}$ & $\begin{array}{c}\mathbf{T}_{\mathbf{5 0}} \\
{\left[{ }^{\circ} \mathbf{C} \mathbf{C}\right.}\end{array}$ & $\begin{array}{c}\mathbf{T}_{\mathbf{7 5}} \\
{\left[{ }^{\circ} \mathbf{C}\right]}\end{array}$ & $\begin{array}{c}\mathbf{T}_{\mathbf{p T P S}} \\
{\left[{ }^{\circ} \mathbf{C}\right]}\end{array}$ & $\begin{array}{c}\mathbf{T}_{\mathbf{p P L A}} \\
{\left[{ }^{\circ} \mathbf{C}\right]}\end{array}$ & $\begin{array}{c}\text { Resid. } \\
{[\mathbf{w t} \mathbf{+}]}\end{array}$ \\
\hline PLA & 334 & 348 & 360 & 369 & - & 366 & 1.8 \\
PLA/TPS25 & 298 & 323 & 346 & 363 & 314 & 360 & 4.5 \\
PLA/TPS50 & 264 & 309 & 336 & 360 & 310 & 342 & 8.8 \\
PLA/TPS75 & 248 & 297 & 318 & 340 & 315 & 329 & 10.3 \\
TPS & 252 & 295 & 315 & 329 & 322 & - & 10.1 \\
\hline
\end{tabular}

The effect of different compatibilizers on the thermal stability of PLA/TPS blends were also examined. The TGA and DTG curves are shown in Fig. 6a and Fig 6b, respectively. It can be observed that the presence of MA and bHDI does not change the thermal stability of PLA/TPS blends significantly. The CE, however, increased all the T-values by $2-6^{\circ} \mathrm{C}$. 


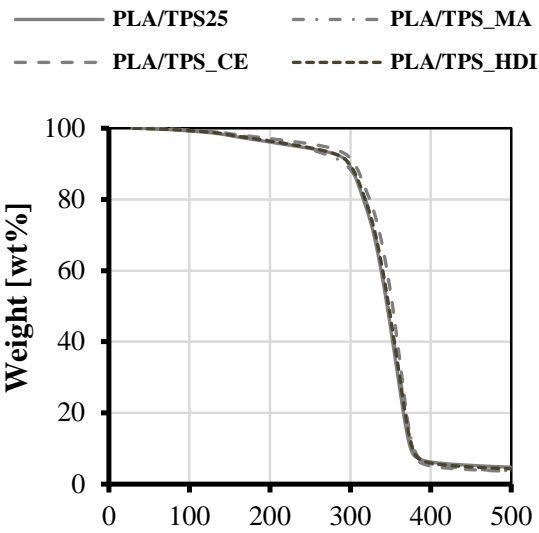

a)

Temperature $\left[{ }^{\circ} \mathrm{C}\right]$
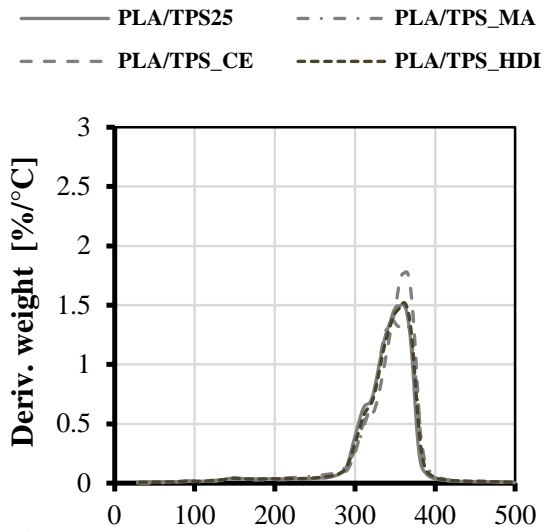

b)

Temperature $\left[{ }^{\circ} \mathrm{C}\right]$

Figure 6. TGA (a) and DTG (b) curves of PLA/TPS25 and its compatibilized variants The related data are summarized in Table 4.

Table 4. TGA data of the PLA/TPS25 blend and its compatibilized variants

\begin{tabular}{c|ccccccc}
\hline Sample & $\begin{array}{c}\mathbf{T}_{\mathbf{1 0}} \\
{\left[{ }^{\circ} \mathbf{C}\right]}\end{array}$ & $\begin{array}{c}\mathbf{T}_{\mathbf{2 5}} \\
{\left[{ }^{\circ} \mathbf{C}\right]}\end{array}$ & $\begin{array}{c}\mathbf{T}_{\mathbf{5 0}} \\
{\left[{ }^{\circ} \mathbf{C}\right]}\end{array}$ & $\begin{array}{c}\mathbf{T}_{\mathbf{7 5}} \\
{\left[{ }^{\circ} \mathbf{C}\right]}\end{array}$ & $\begin{array}{c}\mathbf{T}_{\mathbf{p T P S}} \\
{\left[{ }^{\circ} \mathbf{C}\right]}\end{array}$ & $\begin{array}{c}\mathbf{T}_{\mathbf{p P L A}} \\
{\left[{ }^{\circ} \mathbf{C}\right]}\end{array}$ & $\begin{array}{c}\text { Resid. } \\
{[\mathbf{w t} \%]}\end{array}$ \\
\hline PLA/TPS25 & 298 & 323 & 346 & 363 & 314 & 360 & 4.5 \\
PLA/TPS_MA & 293 & 325 & 347 & 365 & 318 & 362 & 3.8 \\
PLA/TPS_bHDI & 299 & 326 & 347 & 365 & 315 & 359 & 4.0 \\
PLA/TPS_CE & 305 & 331 & 352 & 367 & 317 & 366 & 3.7 \\
\hline
\end{tabular}

\section{Conclusions}

The effect of three different coupling agents (namely MA, bHDI and CE) on PLA/TPS blends were examined in this study. The results of the mechanical and morphological tests showed that blends consisting of neat PLA and TPS exhibit a rather poor interfacial adhesion. According to the SEM images all three chemical connectors improved the adhesion between the components leading to a stable, homogenous fracture surface. However, the improvement in tensile mechanical properties were marginal. Out of the three examined coupling agents the CE proved to be the most effective, even though it was the one being introduced in the smallest amount (0.5 wt\%). The samples that contained CE exhibited a 20\% higher yield strength and elongation than the neat PLA/TPS at constant Young's modulus. The TGA tests showed that MA and bHDI does not affect the thermal stability of the blends, the CE however increases it slightly. 


\section{Acknowledgement}

The research was carried out as part of the EFOP-3.6.2-16-2017-00016 project in the framework of the New Széchenyi Plan. The work reported here was supported by the Hungarian Research Fund (OTKA) through the project K 109409.

\section{References}

[1] R. F. T. Stepto, Thermoplastic Starch, Macromolecular Symposia 279 (1) (2009) pp. 163-168.

doi: https://doi.org/10.1002/masy.200950525

[2] H. Liu, F. Xie et al., Thermal processing of starch-based polymers, Progress in Polymer Science 34 (12) (2009) pp. 1348-1368.

doi: https://doi.org/10.1016/j .progpolymsci.2009.07.001

[3] T. Singh, B. Gangil et al., Agriculture waste reinforced corn starch-based biocomposites: effect of rice husk/walnut shell on physicomechanical, biodegradable and thermal properties, Materials Research Express 6 (4) (2019) 045702.

doi: $h$ ttps ://doi .org/10.1088/2053-1591/aafe45

[4] J. Muller, C. Gonzalez-Martinez, A. Chiralt, Combination of Poly(lactic) Acid and Starch for Biodegradable Food Packaging, Materials 10 (8) (2017) 952. doi: https ://doi .org/10.3390/ma10080952

[5] M. Gáspár, Z. Benkő et al., Reducing water absorption in compostable starchbased plastics, Polymer Degradation and Stability 90 (3) (2005) pp. 563-569. doi: https ://doi .org/10.1016/j . polymdegradstab. 2005.03.012

[6] L. Lendvai, A. Apostolov, J. Karger-Kocsis, Characterization of layered silicate-reinforced blends of thermoplastic starch (TPS) and poly(butylene adipate-co-terephthalate), Carbohydrate Polymers 173 (2017) pp. 566-572. doi: https://doi.org/10.1016/j.carbpol.2017.05.100

[7] D. Garlotta, A Literature Review of Poly(Lactic Acid), Journal of Polymers and the Environment 9 (2) (2001) pp. 63-84.

doi: $h$ ttps ://doi .org/10 . 1023/A : 1020200822435

[8] L. Kotrocz, P. Bakonyi, Pinpoint Loading Examinations of Poly(lactic acid) Biopolymers, Acta Technica Jaurinensis 11 (4) (2018) pp. 206-217. doi: https://doi.org/10.14513/actatechjaur.v11.n4.480

[9] N. A, X. Li et al., Starch/polylactide sustainable composites: Interface tailoring with graphene oxide, Composites Part A: Applied Science and 
Manufacturing 69 (0) (2015) pp. 247-254.

doi: $h t t p: / / d x . d o i . o r g / 10.1016 / j$. compositesa.2014.11.025

[10] R. Acioli-Moura, X. S. Sun, Thermal degradation and physical aging of poly(lactic acid) and its blends with starch, Polymer Engineering and Science 48 (4) (2008) pp. 829-836.

doi: https://doi.org/10.1002/pen.21019

[11] Z. Xiong, L. S. Zhang et al., Effect of castor oil enrichment layer produced by reaction on the properties of PLA/HDI-g-starch blends, Carbohydrate Polymers 94 (1) (2013) pp. 235-243.

doi: https ://doi .org/10.1016/j . carbpol.2013.01.038

[12] M. A. Huneault, H. Li, Morphology and properties of compatibilized polylactide/thermoplastic starch blends, Polymer 48 (1) (2007) pp. 270-280. doi: https ://doi .org/10.1016/j . polymer . 2006 .11.023

[13] V. H. Orozco, W. Brostow et al., Preparation and Characterization of Poly(Lactic Acid)-g-Maleic Anhydride + Starch Blends, Macromolecular Symposia 277 (1) (2009) pp. 69-80. doi: https://doi.org/10.1002/masy. 200950309

[14] Y. C. Zhang, X. Yuan et al., The Effect of Polymeric Chain Extenders on Physical Properties of Thermoplastic Starch and Polylactic Acid Blends, Journal of Polymers and the Environment 20 (2) (2012) pp. 315-325. doi: https ://doi .org/10.1007/s10924-011-0368-3

[15] H. Li, M. A. Huneault, Effect of chain extension on the properties of PLA/TPS blends, Journal of Applied Polymer Science 122 (1) (2011) pp. 134-141. doi: https ://doi.org/10.1002/app. 33981

[16] M. L. Sanyang, S. M. Sapuan et al., Development and characterization of sugar palm starch and poly(lactic acid) bilayer films, Carbohydrate Polymers 146 (2016) pp. 36-45.

doi: https ://doi .org/10.1016/j . carbpol . 2016 . 03.051

[17] A. Ujcic, M. Nevoralova et al., Thermoplastic Starch Composites Filled With Isometric and Elongated TiO2-Based Nanoparticles, Frontiers in Materials 6 (284) (2019)

doi: https://doi.org/10.3389/fmats. 2019.00284 